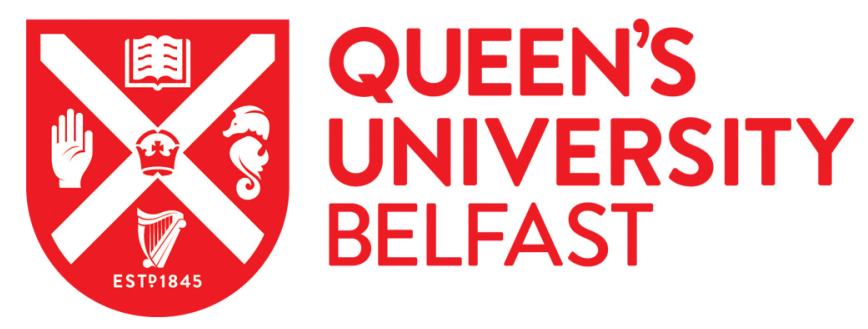

\title{
Additive Manufacturing can assist in the fight against COVID-19 and other pandemics and impact on the global supply chain
}

Larrañeta, E., Dominguez Robles, J., \& Lamprou, D. (2020). Additive Manufacturing can assist in the fight against COVID-19 and other pandemics and impact on the global supply chain. 3D Printing and Additive Manufacturing. https://doi.org/10.1089/3dp.2020.0106

Published in:

3D Printing and Additive Manufacturing

Document Version:

Peer reviewed version

Queen's University Belfast - Research Portal:

Link to publication record in Queen's University Belfast Research Portal

Publisher rights

( 2020 Mary Ann Liebert, Inc.This work is made available online in accordance with the publisher's policies. Please refer to any applicable terms of use of the publisher.

\section{General rights}

Copyright for the publications made accessible via the Queen's University Belfast Research Portal is retained by the author(s) and / or other copyright owners and it is a condition of accessing these publications that users recognise and abide by the legal requirements associated with these rights.

Take down policy

The Research Portal is Queen's institutional repository that provides access to Queen's research output. Every effort has been made to ensure that content in the Research Portal does not infringe any person's rights, or applicable UK laws. If you discover content in the Research Portal that you believe breaches copyright or violates any law, please contact openaccess@qub.ac.uk. 


\title{
Additive Manufacturing can assist in the fight against COVID-19 and other pandemics and impact on the global supply chain
}

\author{
Eneko Larrañeta ${ }^{1}$, Juan Dominguez-Robles ${ }^{1}$, Dimitrios A. Lamprou ${ }^{1 *}$ \\ ${ }^{1}$ School of Pharmacy, Queen's University Belfast, 97 Lisburn Road, Medical Biology Centre, \\ Belfast BT9 7BL, UK \\ * For correspondence: email: d.lamprou@qub.ac.uk, tel.: +44 (0)28 90972617
}

\begin{abstract}
The high demand on medical devices and Personal Protective Equipment (PPE) during the COVID-19 crisis, left millions of healthcare professionals unprotected in the middle of this situation, as governments around the world were not prepared for such pandemic. The 3D printing (3DP) community, from Universities to 3DP enthusiasts with printers at home, was there to support hospitals from day one on this demand by providing PPE and other medical supplies (e.g. face shields and valves for respiratory machines). This editorial, will cover the importance of 3DP in the fight against COVID-19 and how this can be used to tackle potential pandemics and support the supply chain.
\end{abstract}

Keywords: 3D printing, additive manufacturing, COVID-19, medical devices, pandemic, PPE, supply chain.

\section{Introduction: COVID-19 and supply-chain}

After a series of cases of pneumonia in Wuhan, the capital city of Hubei province (China), the Chinese health authorities announced in January 2020 that a novel coronavirus, officially known as severe acute respiratory syndrome coronavirus 2 (SARS-CoV-2) was the responsible for these cases. ${ }^{1}$ SARS-CoV-2, the virus that causes the coronavirus disease (COVID-19) was not detected before the recent pandemic and has been known to be genetically similar to severe acute respiratory syndrome coronavirus (SARS-CoV). ${ }^{1}$ The COVID-19 is transmitted mainly through contact with an infected individual, through droplets that are produced when the patient coughs or sneezes or through droplets from the saliva or nasal cavity. ${ }^{1,2}$ In order to avoid transmission, is very important to implement individual hygiene measures and especially the use of personal protective equipment (PPE). However, the lack of PPE and other key resources during the COVID-19 crisis has been a constant problem, leaving many healthcare professionals across the world unprotected.

Dealing with a pandemic, such as COVID-19, is an unprecedented situation in this modern, globalised word, which has created extraordinary emergency that is particularly affecting the supply chain. ${ }^{3}$ The supply chain disruptions, in combination with the enormous needs for medical devices and protective healthcare material, have created the need of new initiatives and the use of emerging technologies such as 3D printing (3DP) to come forward and support the healthcare professionals and supply chain. 


\section{Additive manufacturing for healthcare professionals}

\subsection{The "citizen supply chain"}

3DP is an additive manufacturing (AM) technique, which is able to produce physical models by adding materials layer-by-layer based on a computer-aided design (CAD) (Figure 1), and permits the manufacturing of variety of items in a cost-effective and fast approach. ${ }^{4}$ There are several 3D printing technologies in existence, including fused deposition modeling (FDM), which is a form of material extrusion, which is by far the most common due to its ease of use, low cost and broad range of material choice. ${ }^{5}$

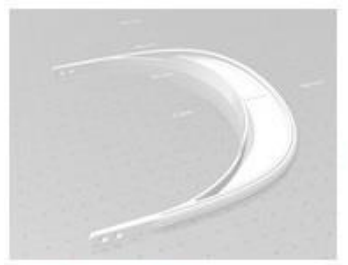

Step 1: Design

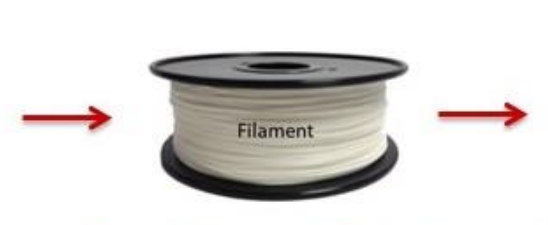

Step 2: Materials Selection

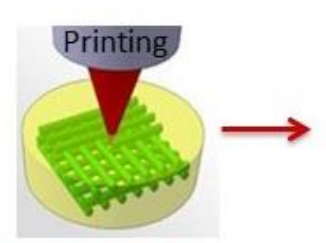

Step 3: 3D Printing

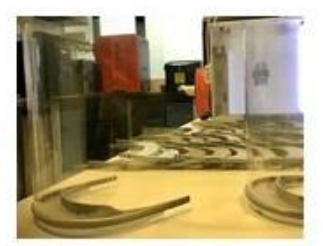

Step 4: Final Product

FIG. 1 Fused deposition modeling 3DP process of a face shield.

Due to the versatility, 3DP has been used by many researchers to develop new prototypes. Among all the applications 3DP has been recently used for the manufacture of a range of drug delivery systems and medical devices. ${ }^{4,6,7}$ Despite of these recent developments, 3DP is not a new technique as the first patent describing this technology was filled in the late $80 \mathrm{~s} .{ }^{8}$ However, the field of 3DP experienced a huge increase in popularity during the last 15 years due to the "democratisation" of this technology. This process started in 2005 with the project RepRap aiming to develop an open source community to make 3DP technology accessible to everybody. ${ }^{8}$ Thanks to this program nowadays 3DP equipment can be found at affordable prices making it accessible to the general public.

The "democratisation" of 3DP combined with the COVID-19 crisis lead to an unprecedented situation. Everybody with a 3DP equipment at home could be part of a "citizen supply chain". A "maker" community leaded by skilled engineers started working on the demand of PPE and other healthcare products by mainly using 3D printers and household materials, by providing freely support and access to their designs over the internet. Everyone with a 3D printer at home was able to access these designs and prepare face shields/visors and other important required devices. The "maker" or "citizen supply chain" community across the world, with collaborators from industrial and academic institutions, organised and stablished enormous networks in short period, to distribute 3D printed items to healthcare professionals. This initiative is the biggest "collaborative project" in the modern history following the spirit of the "RepRap2 initial project.

\section{$2.23 D$ printed medical devices and personal protective equipment (PPE)}

In the last months 3DP has been constantly in the news, from companies that they know-how to produce with 3DP techniques, to volunteers finding solutions in treatment procedures and support local communities. An example of different 3D printed items that have been reported so far can be found in Table 1. Is very important to emphasize that not all 3DP items that have been reported are appropriate to be used in COVID-19 health centres prior of getting 
approval by a regulatory body (e.g. US Food and Drug Administration (FDA)), as have to provide a certain degree of protection to these healthcare professionals and/or have to be safe for the patients (e.g. use of valves, ventilators).

Table 1. 3D Printed examples, reported in the news, in the fight against COVID-19.

\begin{tabular}{cc}
\hline 3DP Type & 3DP items to support healthcare professionals \\
\hline FDM & Hand sanitiser holders \\
\hline FDM & Door handle attachments \\
\hline FDM & Screw less hands-free door handle openers \\
\hline FDM & Visors / Face shields \\
\hline FDM & Face masks (e.g. surgical and N95 Respirator) \\
(needs regulatory approval first)
\end{tabular}

One of the first examples is the Milan's Issinova technology company that after an intervention of a journalist, brought a selective laser sintering (SLS) printer to Brescia hospital (Italy) and immediately designed a new valve for oxygen masks by scanning the original design. The device tested on patients and after confirming that the 3DP item was excellent, the company start producing new batches.

Since this first example, the maker community started working actively to develop other pieces of medical devices. The most popular item that has been shared online and 3DP by many groups and individuals worldwide was face shields. Figure 2, shows an example of the 3D printed face shields prepared using FDM. In order for the face shields to be suitable for use in COVID-19 centers, must follow specific standards such as, be close on the forehead, allow safe air ventilation, and at the same time be comfortable for long wearing hours.

Surgical masks and N95 respirators, is another example that many companies and individuals are currently focusing on. However, these systems, need to receive regulatory approval before use, as many 3DP items and/or materials may not provide the same level of barrier protection, fluid resistance, and infection control, especially when are getting wet and coming in contact with viruses. ${ }^{9}$ Many research groups are investigating the incorporation of drug molecules or copper oxide $(\mathrm{CuO})^{10}$ on the manufacture of multi-purpose protective items 
(e.g. masks, goggles) in order to provide an antimicrobial and antiviral protection, which could be used in hospitals for an additional protection.

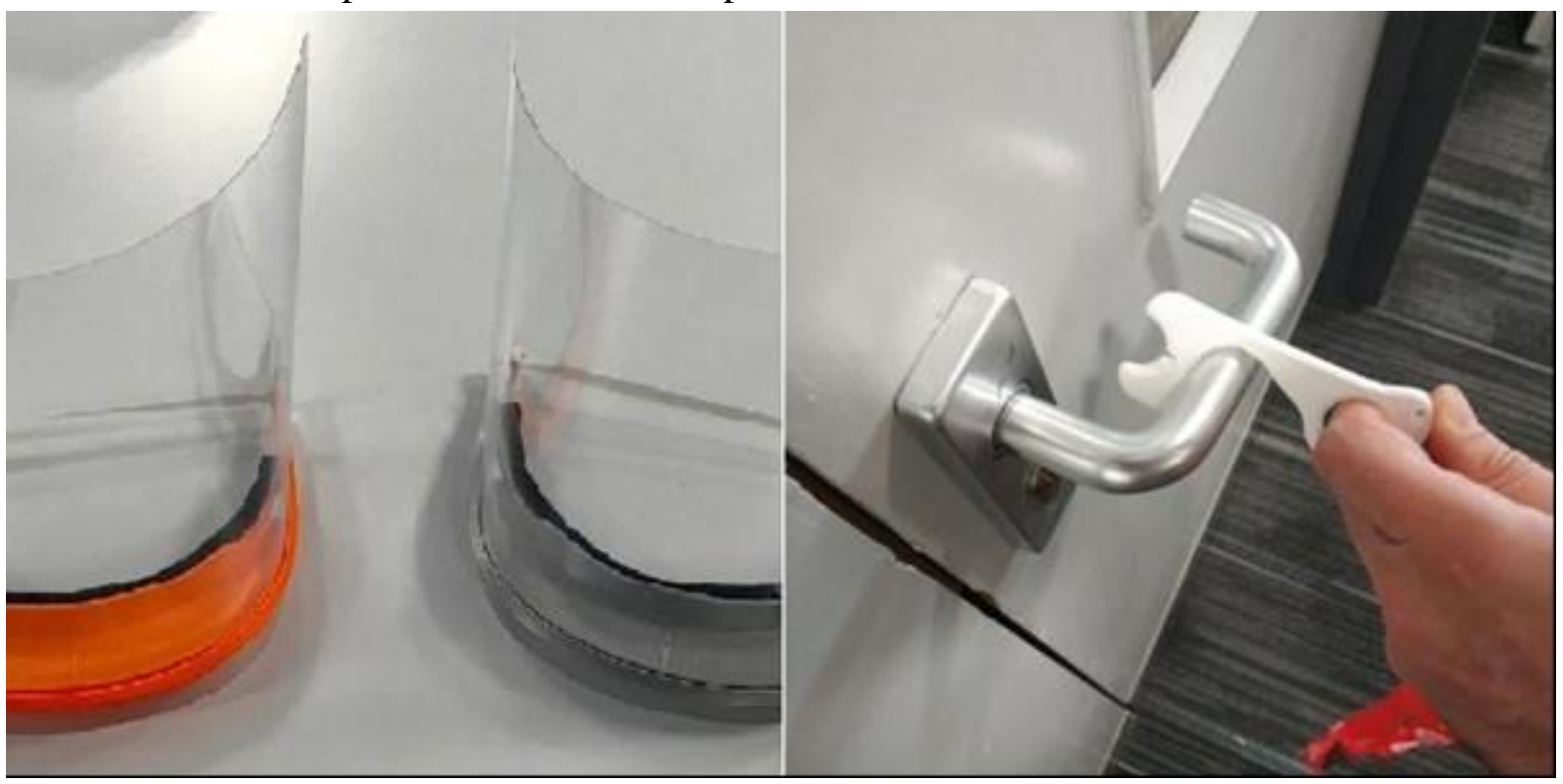

FIG. 2. Examples of 3D printed face shield and door openers prepared by the School of Pharmacy Queen's University Belfast, donated to healthcare professionals. The face shields were made of a 3D printed part (grey/orange part), an acetate sheet as visor, an elastic band and foam to protect the forehead. These designs were approved by the infection control unit of the Belfast Health \& Social Care Trust.

Many print farms have also been an initiative in Europe and US, with 3DP companies offering their in-house facilities to support with the medical device shortage around the world, using mainly three 3DP types: FDM, SLS and SLA. Moreover, Volkswagen, Nissan, Ferrari, Airbus, and BMW are some of the big manufacturers that have also used their facilities to manufacture medical products using 3DP.

All these examples have shown that 3DP is nowadays an emergent valuable technology to support in a pandemic and boost supply chain. Very soon, every hospital will have a 3DP department that will be responsible manufacturing bespoke items in-house.

\section{Conclusions}

3DP has supported with the shortage of medical supplies and transform manufacturing by enabling individuals and companies to produce items in the fight against COVID-19 using printers with costs as low as $\$ 250$. The “citizen supply chain" has proven to be a strong initiative/solution to unlock the potential of 3DP in future supply chains and be a gamechanger in many industrial sectors. However, is very important all safety considerations/regulations to be follow when a 3DP item is proposed to be used in a hospital environment as not all designs or/and materials used can provide an appropriate physical barrier. 


\section{Acknowledgments}

The authors would like to thank the technical staff at the School of Pharmacy at Queen's University Belfast (QUB) for all their support with 3D printing during the pandemic and Belfast Trust for all their advices on PPE safety considerations and QUB for covering the costs for all PPE donations.

\section{Author Disclosure Statement}

No competing financial interests exist.

\section{References}

1) Rothan HA, Byrareddy SN. The epidemiology and pathogenesis of coronavirus disease (COVID-19) outbreak. Journal of autoimmunity 2020; 109:102433.

2) Wölfel R, Corman VM, Guggemos W, et al. Virological assessment of hospitalized patients with COVID-2019. Nature 2020. https://doi.org/10.1038/s41586-020-2196-X.

3) Patel R, Babady E, Theel ES, et al. Report from the American Society for Microbiology COVID-19 International Summit, 23 March 2020: Value of Diagnostic Testing for SARS-CoV-2/COVID-19. mBio 2020; 11 (2) e00722-20.

4) Mathew E, Domínguez-Robles J, Larrañeta E, Lamprou DA. Fused Deposition Modelling as a Potential Tool for Antimicrobial Dialysis Catheters Manufacturing: New Trends vs. Conventional Approaches. Coatings 2019; 9: 515.

5) Shahrubudin N, Leea TC, Ramlan R. An Overview on 3D Printing Technology: Technological, Materials, and Applications. Procedia Manufacturing 2019;35:12861296.

6) Domínguez-Robles J, Mancinelli C, Mancuso E, et al. 3D Printing of Drug-Loaded Thermoplastic Polyurethane Meshes: A Potential Material for Soft Tissue Reinforcement in Vaginal Surgery. Pharmaceutics 2020; 12: 63.

7) Stewart SA, Domínguez-Robles J, McIlorum VJ, et al. Development of a Biodegradable Subcutaneous Implant for Prolonged Drug Delivery Using 3D Printing. Pharmaceutics 2020; 12: 105 .

8) Paull B, Nesterenko P, Gupta V. An Introduction to 3D Printing. In: 3D Printing in Chemical Sciences: Applications Across Chemistry. Royal Society of Chemistry, 2019, pp. 1-21.

9) U.S. Food \& Drug administration (FDA). 3D Printing of Medical Devices. https://www.fda.gov/medical-devices/products-and-medical-procedures/3d-printingmedical-devices. Accessed date 13 April 2020.

10) Vincent M, Duval RE, Hartemann P, Engels-Deutsch M. Contact killing and antimicrobial properties of copper. Journal of Applied Microbiology 2017;124: 10321046. 